\title{
Mass Timber in High-Rise Buildings: Modular Design and Construction; Permitting and Contracting Issues
}

\author{
Dalia H. Dorrah ${ }^{1 *}$ and Tamer E. El-Diraby ${ }^{2}$ \\ ${ }^{1}$ PhD candidate, Department of Civil Engineering, University of Toronto \\ ${ }^{2}$ Associate Professor, Department of Civil Engineering, University of Toronto \\ "Corresponding author's e-mail: dalia.dorrah@mail.utoronto.ca
}

\begin{abstract}
Due to the inherent inefficiencies in conventional approaches followed in the construction industry and the global demand for lean and sustainable construction techniques, modular construction has witnessed a resurge especially in high-rise buildings. As such, much efforts have been put in studying the use of mass timber for the main structure of high-rise buildings in order to ensure more sustainable developments with high levels of adaptability. In this regard, previous research efforts have primarily focused on the added benefits of mass timber, its structural design and performance, and associated safety requirements. However, owing to the novelty in combining modular processes with timber materials and associated lack of data, several regulatory barriers and contractual issues still exist. To mitigate these issues, this paper studies the specifics of permit approvals and contracting issues in timber high-rise modular buildings. The objective is to develop a comprehensive up-to-date review and analysis of the relevant practices and to conduct interviews with industry experts to analyze their concerns, given the insufficient number of guides and building codes that dealt with these issues. Hence, our study investigates the process of obtaining permit approvals from local jurisdictions in Ontario in addition to the requirements for submission of additional documentation, engineering analysis, and testing. Moreover, it analyzes the initial stage of contractual agreement of stakeholders under the uncertainties imposed on these buildings and evaluates the suitability of Integrated Project Delivery (IPD) contracting method. Presenting detailed analysis of the initial planning stages for timber high-rise modular buildings can in turn suggest the best practices to be taken into consideration for the successful implementation of these buildings under the current building code.
\end{abstract}

\section{KEYWORDS}

Modular Construction; Mass Timber; High-Rise Buildings; Permits; Fire Safety; Contracting

\section{INTRODUCTION}

The land development and construction industries are changing very fast. This is due to factors as increased urbanization and rising demands for sustainability, the advent of smart building and artificial intelligence, and the growing role of customers in decision making and co-creation of knowledge. A relatively new domain, particularly in Canada, is the use of mass timber as the main structural element in high rise buildings in combination with modular construction approaches. 
Timber has lower climate change impact in the order of $34 \%$ to $84 \%$ compared to steel and concrete (Skullestad et al., 2016). This means that replacing steel and concrete with timber can certainly reduce the building sector contribution to GHG emission. Moreover, adopting mass timber in high rise buildings can positively contribute to energy management and resource conservation for its low embodied energy compared to concrete and steel, can be appealing to customers for its bold architectural feature and can enable testing and advancing the resiliency and innovation capacity of developers and contractors. Nevertheless, modular construction is a key to lean and green construction practices. The advantages of modular construction include: design only once and reuse multiple times; design and procure in advance/respond to schedule needs; accelerated, parallel engineering for site adaptation; learning curve in commissioning, planning and execution, fabrication, module installation and site construction, and operations and maintenance; volume discounts in procurement; operations and maintenance; and material management cost savings (O'Connor et al., 2015). Following modular design and construction approaches in timber structures can significantly improve their sustainability and open new horizons for innovation. However, in Ontario, the uncertainties and risks associated with such structures are under-studied given the insufficient guides and building codes for these structures. This mainly includes permitting and code compliance particularly regarding fire performance and safety as well as coordination problems between stakeholders. This shortcoming hinders the innovative exploration and the successful execution of such new systems, and with the increased risks more costs are incurred.

This study is based on an extensive review of literature investigating technical aspects of modularization and mass timber structures quantifying the benefits and drawbacks as well as challenges, risk and best practices for these structures. It also investigates relevant issues and related work to analyze the feasibility and constructability of using mass timber in high-rise modular structures under the current building code. This study is complemented by a set of interviews with industry experts and relevant stakeholders to further enrich the analysis particularly regarding the specifics of permit approvals in Ontario and the issues in contracting agreements. The paper is divided into five main sections. After the introduction, the scope and methodology of the study are explained in section two. Section three shows the case studies and interviews performed in the study. Section four provides the discussion and analysis of the review performed. Finally, section five gives the main conclusions and recommendations.

\section{METHODS}

The main objective of the study is to develop a case-based analysis framework for modular construction in combination with mass timber in high rise buildings. The scope of the study directed the analysis towards the relationship between mass timber structure and modular construction with more consideration given to fire safety and local construction knowledge as they relate to mass timber--there is a clear need for integration between these two domains. The steps for the methodology are outlined as illustrated in Figure 1. After identifying the scope, the objective is achieved by developing a state of the art review and analysis of the practice which is centered around conducting and evaluating case studies. This is proceeded with an extensive review of literature, where the main focus will include investigating technical aspects of modularization; quantifying the benefits, drawbacks, challenges, risks and best practices of modularization; exploring the use of timber in high-rise buildings; and identifying the main issues hindering the wide adoption of timber structures. 
This review enables modifying the scope and guiding the design of case studies and interviews. Case studies and interviews with industry experts are then conducted and the results are analyzed. From the performed analysis, the main recommendations and lessons learned are outlined. The details methodology of the research is specified in the following Section.

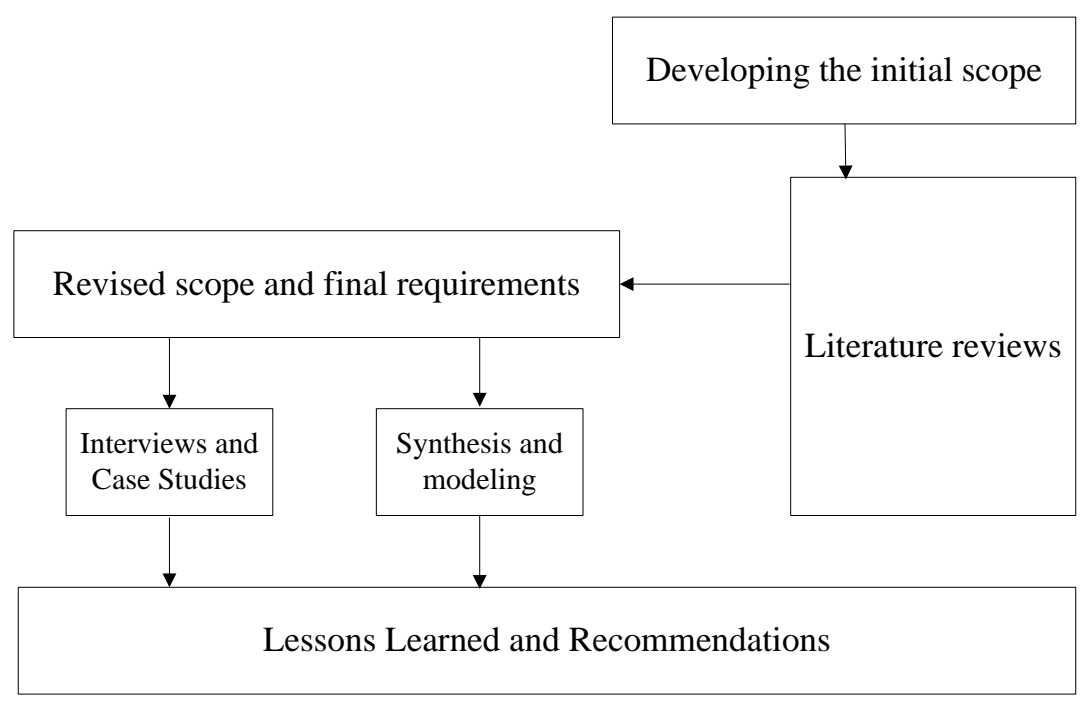

Figure 1. Methodology of Research

\section{IMPLEMENTATION OF METHODOLOGY}

The implementation of the five components of the methodology is explained in the following subsections.

\section{Literature Reviews}

Literature reviews mainly review modularity-related research work and relevant cases in the use of mass timber. Special emphasis is placed on four issues: 1) the role of modularity in reducing construction costs, 2) the importance of modularity in supporting adaptive buildings and use reconfiguration, 3) the technologies and types of timber sections, and their performance under fire, and 4) the process of permit approvals for high-rise timber structures and contracting issues.

\section{Interviews and Case Studies}

Interviews are conducted with experts in design, construction, and maintenance to complement the literature reviews, analyze their concerns and recommendations, help select project cases, evaluate the analysis of the cases, and enhance the quality and relevance of the recommendations. The research investigated relevant cases in the use of timber in high rise buildings. The case studies included information from published projects and from conducting two Canadian case studies. Examples of the explored published cases for high rise timber buildings include buildings as Origine in Quebec city, Wood Innovation and Design Center in British Columbia, Albina Yard, Carbon 12, and The Radiator buildings in Portland-Oregon, Forte Living Building in Melbourne-Australia, Arbora Complex in Montreal, and others. 
The investigation included studying their main features, fire safety procedures, and challenges. Aside from the published cases, the two Canadian case studies developed are the University of British Columbia Brock Commons Project which has been completed in 2017 and the University of Toronto New Academic Wood Tower which is still in the design phase.

\section{Synthesis and Modeling}

This step reflects the process of conducting iterative analysis of the challenges and opportunities, risks and best practices. From the case studies and interviews conducted, more emphasis is placed on issues of permitting and code compliance - the process of submitting alternative solutions under Ontario's Building Code (OBC), as well as examining the contracting issues in high rise timber buildings in light of the available experience of stakeholders and the shortcomings of the traditional project delivery methods. It is clear that two issues of major significance hinder the wide adoption of mass timber structures. These issues are permitting and code compliance particularly in regards to fire safety, and the newness of the system which may be perceived as increased risk by contractors. These issues cause mass timber structures in Ontario to cost more than conventional concrete or steel structures.

Permitting and Code Compliance in Ontario. The regulation of building construction in Ontario still did not present specific acceptable solutions for tall wood buildings. Therefore, until prescriptive set of provisions were available as an acceptable solution to design and construct tall wood buildings, the submission of alternative solutions is a requirement for permitting tall wood buildings. In addition, every tall mass timber building project will require a fire safety engineer to put together a detailed alternative solution with an engineering analysis. Alternative solutions typically include additional engineering analysis and testing (or results from relevant testing) to demonstrate the fire safety performance set based on the current acceptable solutions in Division $\mathrm{B}$ of $\mathrm{OBC}$ to be considered by building officials. In general, reliable and safe structural performance for mass timber structures in fire can be achieved through charring and encapsulation in addition to modern fire suppression systems (Ontario's Tall Wood Reference, 2017; Hasburgh, 2016). However, encapsulation could defy the architectural appeal of such structures. Despite the combustibility of mass timber, there were no known incidents of major fires in built mass timber structures which made post-fire repairs not commonly practiced. But the rehabilitation of such structures, including replacing damaged sections, doesn't seem to be more difficult or expensive than the case of fires in concrete or steel structures. Moreover, regarding permitting agencies, cities of Vancouver and Toronto have taken progressive steps to support expediting the permit process for mass timber structures. In Toronto, a special committee has been overseeing the approvals--especially in relation to fire insulation. Such committee can play a major role in documenting and sharing innovative solutions and best practices as well as setting a supportive research and training agenda.

Novelty of Mass Timber High Rise Structures. The combustible nature of timber and the novelty of mass timber structures in Ontario can add additional costs on the short term for such structures. These costs include: 1) Charges for consulting engineers due to additional time required to study and manage code compliance; 2 ) Charges for a dedicated fire engineer who is a must for any successful development of mass timber structure; 3) Additional fees paid to permitting agencies to process mass timber structures as code and regulations for such structure are not well developed; and 4) Insurance premiums for construction sites and for the building as 
some contractors may add a risk premium given the novelty of the system in Ontario. However, it is expected that such costs and premiums will come down with the spread of mass timber use. Cost and schedule savings associated with modular construction can offset the impacts of increased/perceived construction risk and some of the costs associated with added analyses and tasks in design and permitting. It should be noted that implementing modular construction does not necessitate strict modular designs. The repetitive units can differ in size and complexity or can be limited to the structural elements of the high-rise building (beams, columns, floorings, wall panels, etc.). However, even with the most standardized 3D units, innovative designs can be achieved. Nevertheless, timber construction is a familiar domain to labour force in Ontario in low to mid-rise structures. Mass timber in high-rise will include larger section sizes and new types of connections. The novelty of this should not be a significant issue given the large similarities in construction practices and the fact that almost all mass timber sections are premanufactured, which provide higher accuracy in cuts and dimensions. Finally, experts have reported that the carpenter trade training centers have indicated that providing the required training should not be a significant burden and that modular construction, especially premanufacturing, in mass timber structures offers a major boost to a faster learning curve.

\section{Lessons Learned and Recommendations}

After the synthesis and modeling, this stage summarizes a set of findings from the literature and the case studies and recommends additional work in the future. The most significant lessons learned for various aspects are shown in below subsections.

Timber as a Material. In general, timber requires less equipment and workmanship compared to concrete and steel. This makes timber structures much simpler when they are well planned. Choosing whether to go with $100 \%$ timber or hybrid systems as concrete core, depends mainly on the building geometry and required spans. However, reducing the percentage of timber use in the building in turn reduces its potential benefits. Timber has other benefits compared to concrete and steel including its aesthetic appeal, opportunities for sustainable supply chain when supplied from all over Canada, less embodied energy and carbon emissions, and quicker erection. Also, it has opportunities for prefabrication which increases the construction accuracy and productivity, reduces on-site construction time and waste, and allows for concurrent off-site work to occur in controlled conditions. In addition, the light weight of timber makes it more suitable for building modules for modular construction compared to concrete. Nevertheless, challenges in using timber include the risks imposed by the unfamiliarity with such novel systems which in turn makes stakeholders raise their risk margins. Another challenge is its higher costs because of the limited number of suppliers, the lack of experience, and the fire safety issues.

Permits and Code Compliance. Compliance with building codes has been found to be the main factor challenging the broader adoption of mass timber. Within the scope of current building codes, various buildings were developed using mass-timber at a small scale. However, obtaining permits for high-rise timber buildings is challenging regarding the buildings' fire safety. Several of the case projects analyzed used a two-stage reporting process based on submitting a fire engineering brief and a fire engineering report. The brief communicates the objectives and basic strategy by which the fire safety engineering analysis will be conducted and outlines the proposed alternative solutions. Whereas, the report details the formulation and analysis of the fire safety design solutions to support the recommendations for the formulated fire safety design solution for the building. It is recommended to involve the regulator to be consulted as early as 
possible to review the fire engineering strategy. Also, investment in effective, open and interactive partnership with code agencies and research and testing institutes is an important step to be taken given the novelty and "unchartered" nature of these structures in Ontario. A dedicated program or group should be established to plan and continually update a collective effort to 1) synthesize and benchmark existing knowledge and facts about the structural and fire performance of mass timber; 2) proactively commission testing, simulations and analyses to address any gaps or Ontario-specific needs; 3) consistently reflect the lessons learned in future projects; and 4) use smart monitoring systems to measure actual building performance, study and model behavior, and validate initial assumptions/simulations.

Building Information Modeling (BIM) and Virtual Design and Construction (VDC). BIM can be used to visualize and create scenarios for the spread of fires, study fire management and evacuation procedures, and provide an effective platform for studying the project and comanaging its features as schedule and cost. In modularization, the use of BIM helps streamline planning, design, shop drawings development, manufacturing and construction process. Moreover, physical conflicts between systems can be easily identified early in the design process (Lu and Korman 2010). Areas where BIM can be instrumental in supporting modular construction include clash detection, precast fabrication, and production and delivery sequencing through 4D modeling systems (Ramaji et al. 2014). However, limited work has been done for integrating analysis of modularity in BIM (Becerik-Gerber and Rice 2010). As for VDC systems, integrated design process enhanced by the use of VDC modeling allows developing a comprehensive and highly detailed 3D virtual model of the building that can be used to assess the constructability and cost of different options and identify conflicts, to communicate with trades during the bidding process, and to develop shop drawings. VDC models can be also used in the prefabrication of mass-timber elements and in coordinating systems to reduce the number of design changes while identifying and addressing areas of potential conflict or improvements ahead of time.

Contracting. Being relatively new, the use of mass timber for high-rise buildings has accompanying risks and uncertainty, and requires thorough planning from the early stages. This will require the early engagement of the stakeholders, suppliers, fabricators, etc. To address construction risks, developer and consulting teams should be actively engaged with the contractor. They should collaborate on modeling and sharing risks, training of labour and supervisors, and monitoring productivity. For this regard, owners should consider using the integrated project delivery system (IPD). IPD is a new practice that creates a partnership between the owner and the contractor to share knowledge and work together to innovate, reduce risks, manage the project effectively, and, consequently, share the benefits and rewards (Ashcraft, 2014; Fischer et al., 2017). This helps ensure the completion of the project with the required quality, on budget and on time. Under this contract arrangement, the stakeholders would be engaged throughout the design and construction process. In addition, many of the key construction team members are involved or consulted in the design and preconstruction phases including the mass-timber fabricator, the timber erector, and the concrete forming and placement contractor. Their input regarding the feasibility, constructability, and cost estimating of design decisions was crucial in facilitating and accelerating the construction phase.

Supply Chain of Mass Timber. Experts have reported that the supply chain of mass timber in Canada is evolving but is still not as mature as that of Europe and parts of the United States. 
Ontario supply chain still needs some time to reach adequate levels for realizing the most optimal economics. Calculations by some industry experts show that it is cheaper to source mass timber from Europe. However, European timber, while costing less in cash, is certainly more expensive in its "energy costs" which is contradicting with the lower embodied energy offered by mass timber structures as is considered as one of the key motivations for adopting them. Therefore, developers of mass timber structures must establish a healthy and business-based partnership with manufacturers to streamline and strengthen the supply chain in Ontario. This is needed to not only create economics for such industry, but also to set the standards for this evolving industry, particularly the sustainability standards: how to promote mass timber as a means for wood re-use, how to plan and measure the impact of this sector on sustainability of forests, how to integrate environmental and social costs in the financial models, and how to share best practices across the sector. Currently, timber can be obtained from Vancouver or Quebec with transportation costs representing only a small percentage relative to the overall costs. This means that transportation of timber isn't an issue for these buildings.

Business Resiliency and Innovation. Timber buildings may not be cheaper to build than steel or concrete. However, they could get a premium for the [wood] aesthetic when they are leased out and could offer the opportunity to venture into new and innovative areas. Timber fits the new mindsets of organizations with their changing decision criteria to cover different aspects and not only economical aspects. With the recent increase in mass timber use in new developments, particularly in Toronto, customers are willing to pay more for such facilities. Unfortunately, a segment of users may hesitate to occupy mass timber structures due to perceived risk of fire. Therefore, educating users and engaging them in design work and analysis is important to the business case of such structures. Moreover, it is plausible that the environmental requirements, urban complexity and shortage of skilled labor will make prefabrication and manufacturing of buildings the main stream approach. In this regard, it is possible that timber systems will be superior since they are easier to pre-manufacture and need less equipment capacity on and off site-especially in comparison to pre-cast concrete. Therefore, the decision to experiment with timber construction should be part of any strategic look for construction practices.

\section{CONCLUSION}

The use of mass timber for high-rise buildings is relatively new and there is limited experience in designing, constructing and operating such structures. This study focused on the use of timber in high-rise modular buildings in Ontario by reviewing and analyzing relevant practices and conducting interviews with industry experts. From the analysis it has been found that two significant issues facing mass timber structures are permitting and code compliance, particularly in regards to fire safety, and the newness of the system, which may be perceived as increase risk by contractor. For the time being, these issues cause mass timber structures to cost more. However, most of these challenges will be reduced as the familiarity with the technology increases. The analysis results indicated that high rise timber construction requires more change in management and organizational abilities than the engineering aspects. From the study, the main recommendations for dealing with the discussed issues include: 1) Performing formalized constructability analysis and engaging all stakeholders early on; 2)Using BIM and VDC to identify issues, analyze the constructability of buildings, and allow detailed planning; 3) Using partnering and/or IPD approaches to enable participants to collaborate in an environment of 
planned negotiations, amicable settlements, and high flexibility; 4) Using proper fire protection procedures to provide safety through charring or encapsulation; 5) Designing long-term pre and post construction testing schemes to reach the required fire safety levels; and 6) Strengthening the supply chain in Ontario through a collective effort to reduce costs. Finally, the debate about mass timber versus concrete and steel structures should not be an existential one. However, it should focus on how to complement one with the other to face the expected increased demand for both, the increasing prices for energy and the growing need to promote sustainable development.

\section{ACKNOWLEDGEMENTS}

This paper has been developed as an extension of a research project that was commissioned and funded by Sidewalk Labs Toronto, which is in the process of planning and building a smart development on Lake Ontario shoreline: Quayside project.

\section{REFERENCES}

Ashcraft, H., (2014). "Integrated Project Delivery: Optimizing Project Performance”. Hanson Bridgett LLP.

Becerik-Gerber, B., \& Rice, S. (2010). "The perceived value of building information modeling in the US building industry". Journal of Information Technology in Construction (ITcon), 15(15), 185-201.

Fischer, M., Khanzode, A., Reed, D. and Ashcraft, H.W., (2017). "Integrating Project Delivery". John Wiley \& Sons.

Hasburgh, L., Bourne, K., Dagenais, C., \& Ranger, L. (2016). Fire Performance of Mass-Timber Encapsulation Methods and the Effect of Encapsulation on Char Rate of Cross-Laminated Timber.

Lu, N., \& Korman, T. (2010). "Implementation of building information modeling (BIM) in modular construction: Benefits and challenges". Construction Research Congress 2010: Innovation for Reshaping Construction Practice (pp. 1136-1145).

O'Connor, J. T., O’Brien, W. J., \& Choi, J. O. (2015). "Standardization strategy for modular industrial plants". Journal of Construction Engineering and Management, 141(9), 04015026. a

Ontario's Tall Wood Building Reference. (2017). A Technical Resource for Developing Alternative Solutions under Ontario's Building Code, <https:/www.omfpoa.com/wpcontent/uploads/2017/11/Ontarios-Tall-Wood-Building-Reference-2017.pdf>

Ramaji, I. J., \& Memari, A. M. (2013). "Identification of structural issues in design and construction of multi-story modular buildings". In Proceedings of the 1st Residential Building Design and Construction Conference (pp. 294-303).

Skullestad, J. L., Bohne, R. A., \& Lohne, J. (2016). "High-rise Timber Buildings as a Climate Change Mitigation Measure-A Comparative LCA of Structural System Alternatives". Energy Procedia, 96, 112-123. 